\title{
In den Sand geschrieben
}

\author{
F. Gafner
}

Korrespondenz:

Dr. med. Frank Gafner

Rebgasse 15

CH-4410 Liestal
Ein etwas merkwürdiger Titel? In Kürze würde doch der nächste Windstoss die Schrift verwischen und es blieben vielleicht nur noch feine Spuren und einige eilige Insekten auf dem Sand.

Der Titel soll auch nur eine bildliche Umschreibung für mein handwerkliches Schaffen sein. Mit Pinsel arbeite ich wenig. Spritzen und Sprayen, Kratzen und Schaben, Ritzen und Reiben ersetzen die gebündelten Tierborsten. Bereits auf der rohen Leinwand trage ich zur Vergröberung Muschel- und Quarzsand auf. Auch die Farbe selbst wird damit vermischt und mehr oder weniger dick mit dem Spachtel oder dem Rücken einer flachen Holzkelle verteilt. So kommt es zu Überhöhungen in die dritte Dimension und führt zu recht reizvollen Effekten. Zusätzlich collagiere ich noch häufig mit eingefärbten Papieren oder mit Jute, was die Bildwirkung etwas verfremdet, aber dafür eindrücklich zu beeinflussen vermag.

Sei es Musik, dichterisches Wirken oder Malerei, auf der Suche nach neuen Ufern ist heute das Experiment von souveräner Bedeutung, befreit von den Fesseln akademischer Spielregeln, welche noch in der zweiten Hälfte des 19. Jahrhunderts für die Beurteilung eines Werkes mass-

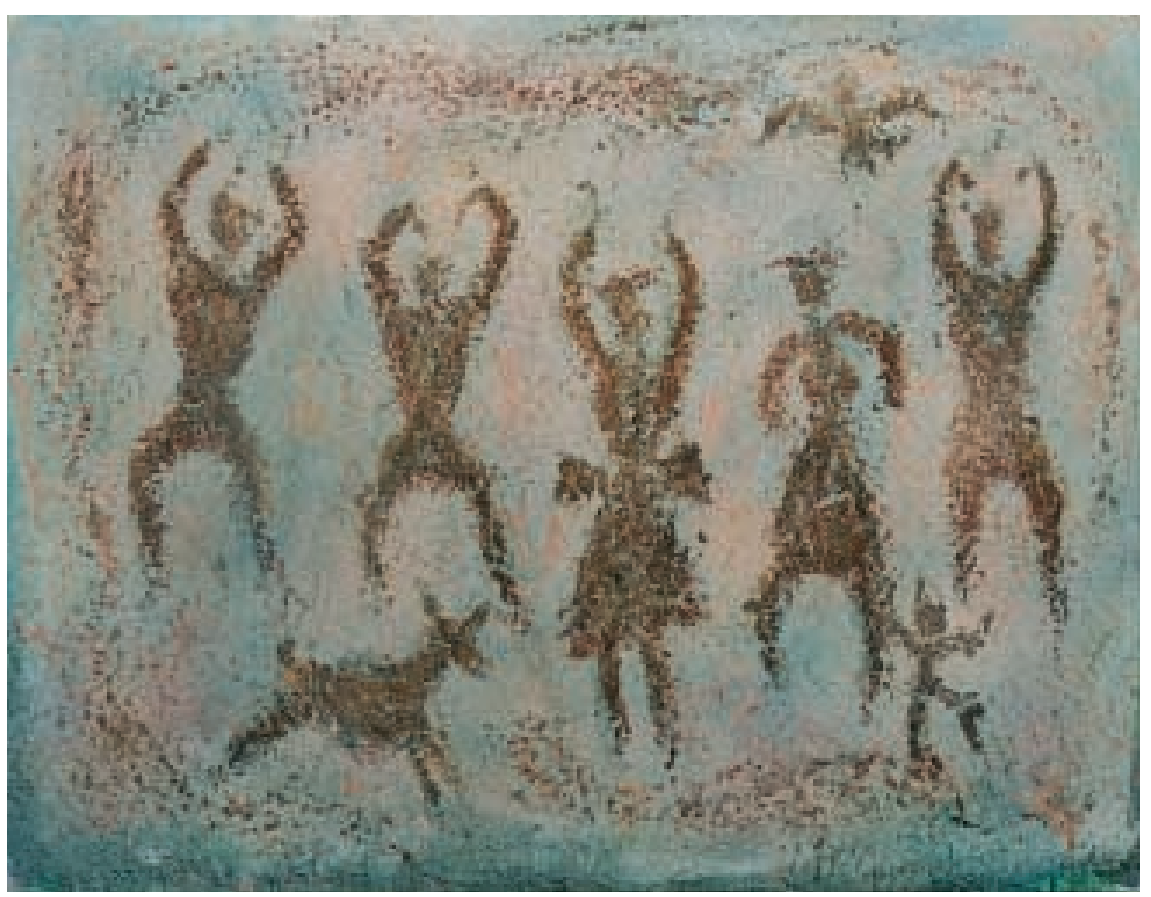

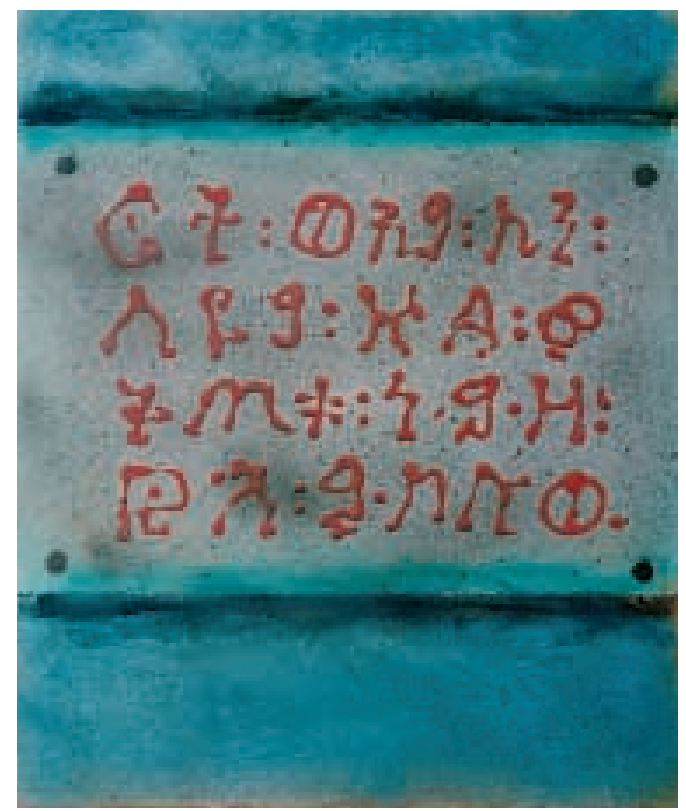

In den Sand geschrieben -

Äthiopische Schrift aus dem 14. Jahrhundert.

geblich waren. Und eben dieses Experimentieren, der Akt des Malens und der persönliche Duktus, die Farbwahl und - besonders für Autodidakten - das nicht genau vorhersehbare Resultat sind spannungsgeladen und im Erfolgsfall beglückend.

Entscheidend ist nicht, ob figuratives Schaffen das Verstehen des Betrachters erleichtert oder ob bei Abstraktion ihm selbst ein schöpferischer Akt zum Verständnis abgefordert wird. Entscheidend bleibt selbstverständlich auch heute die Qualität. Dabei ist mir bewusst, dass gründliche Schulung oder gar Professionalität mir leider fehlen. Wollen und Können sind bekanntlich zwei verschiedene Paar Stiefel.

Ausstellung in der Galerie Rathaus in Liestal (Tel. 06192222 42)

vom 10. Mai bis 15. Juni 2003.

Höhlenballett - Idee aus der Grotte von Magoura (Bulgarien). 

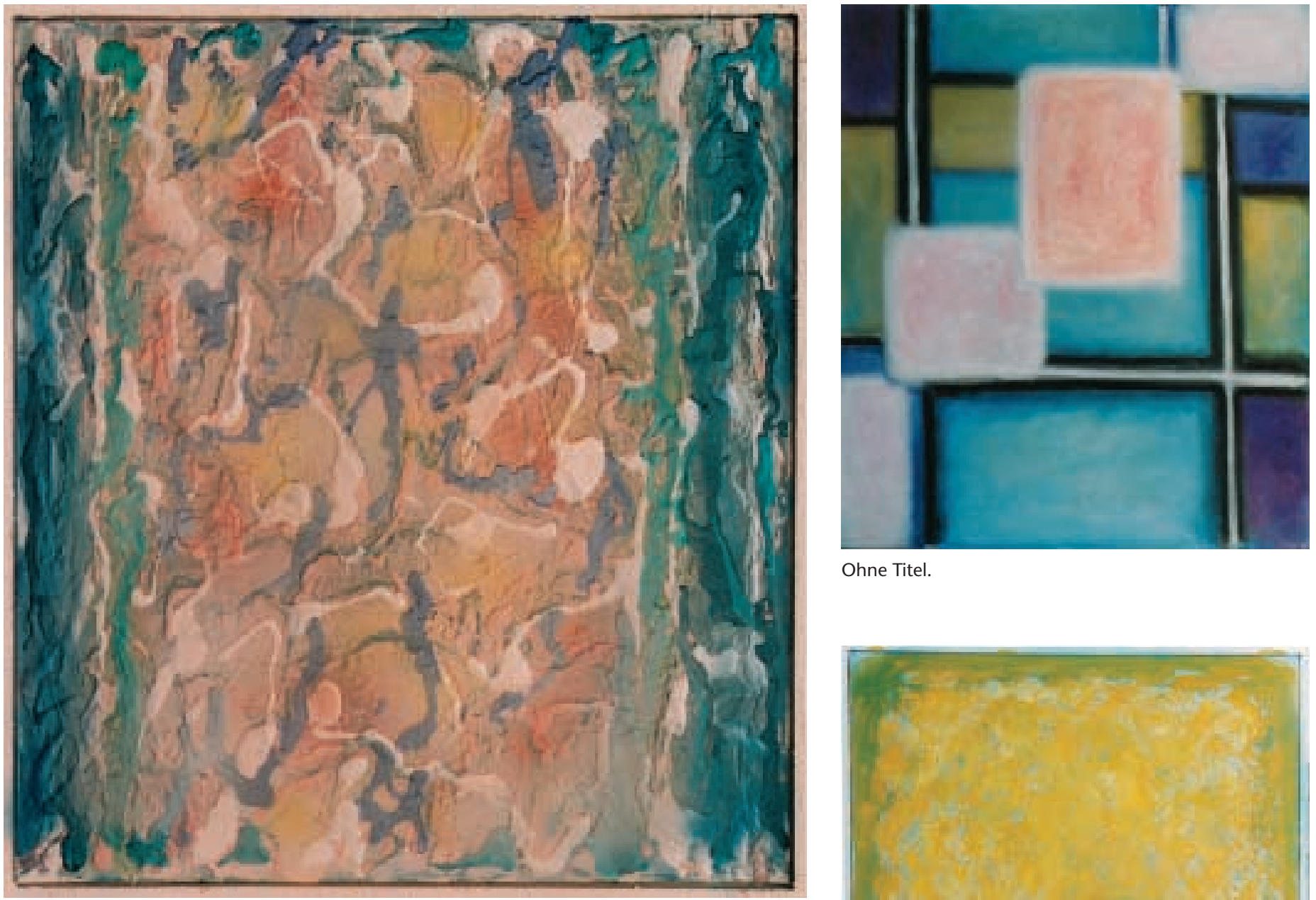

Ohne Titel.

Love Parade Zürich.

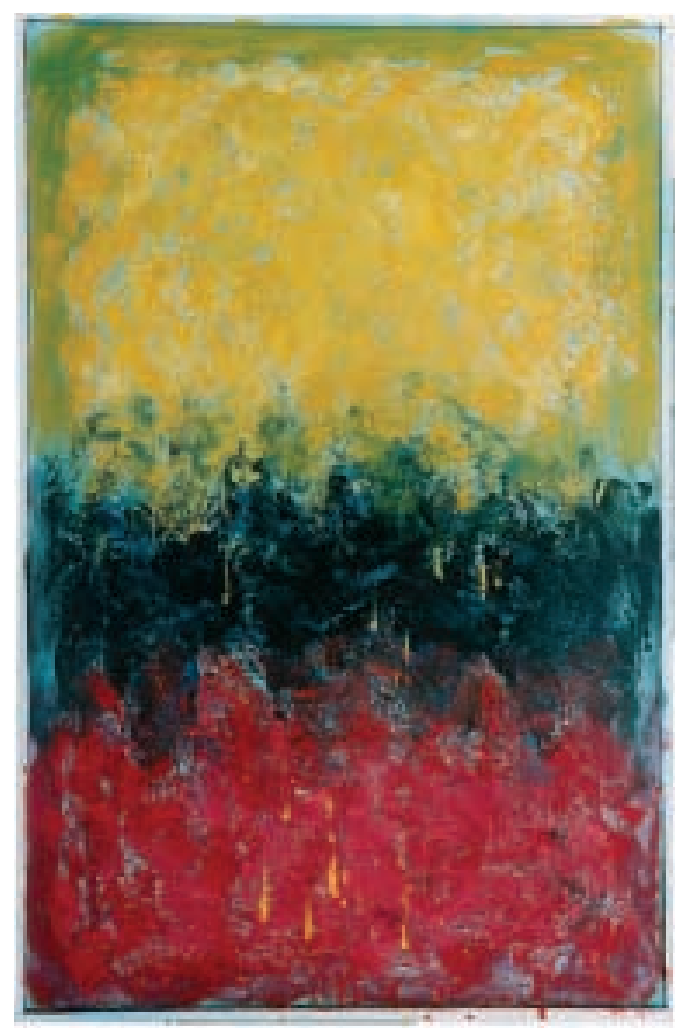

Am Rande des Kraters. 